\title{
Kajian Metode Power Teaching sebagai Alternatif Metode Pembelajaran Sains di Kelas
}

\author{
Eko Nursulistiyo \\ Program Studi Pendidikan Fisika, Universitas Ahmad Dahlan, \\ Kampus III, J1. Prof. Dr. Soepomo, SH, Yogyakarta 55164 Indonesia \\ Surat-e:wajah_rembulan@,yahoo.com
}

Tulisan ini bertujuan untuk studi pustaka mengenai metode pembelajaran Power teaching. Power teaching adalah metode pembelajaran dengan mengacu pada lima langkah pembelajaran yaitu I). Class "Yes", 2). Classroom rules (aturan di dalam kelas), 3). Teach "Okay" (Ajar "Oke"), 4). The Scoreboard, 5). Hands and eyes (tangan dan mata) dan Mirror (pencerminan), 6). Switch. Power teaching sesuai dengan kerucut pengalaman Edgar Dale dan memberikan kontribusi kontribusi 70$90 \%$ dari apa yang dikatakan dan dilakukan karena siswa melakukan pembicaraan (giving a talk) atau presentasi dramatik kepada siswa lainya. Metode Power teaching ini cocok digunakan dalam proses pembelajaran sains/fisika dengan memperhatikan beberapa hal berikut ini I). Konsep yang mudah dipahami dapat diajarkan langsung oleh guru, 2). Konsep yang cukup sulit dapat diajarkan dengan memerintahkan siswa membaca dan memahami kemudian baru mengajarkan kepada teman sebayanya, 3). Evaluasi hendaknya dapat dilakukan untuk mengecek pemahaman siswa karena pembelajaran yang tergolong cepat dan kemungkinan terjadi miskonsepsi, 4). Konsep diajarkan secara bertahap dimana setiap tahapan dijelaskan oleh guru dan dipahami oleh siswa sehingga siswa mendapatkan pemahaman yang utuh dan dimengerti pada akhirnya, 5). Materi yang terlampau sulit bagi siswa harus dipikirkan ulang bagaimana menganjarkanya kepada siswa dengan metode ini.

Kata kunci: metode pembelajaran, power teaching, pembelajaran sains

\section{Pendahuluan}

Menurut PISA (2009) sains Indonesia mempunyai skala 383 di bawah Thailand dengan skala 425. Indonesia juga berada pada rata-rata skala sains dunia oleh PISA yaitu pada skala 50I. Oleh karena itu diperlukan berbagai metode dalam proses pembelajaran agar siswa lebih menguasai materi sains yang diajarkan. Menurut Ihat Hatimah (2008) Metode pembelajaran adalah merupakan suatu cara dalam rangka pencapaian tujuan. Banyak sekali macam-macam metode pembelajaran yang berkembang. Hal ini terjadi karena tuntutan proses pembelajaran, kondisi pembelajaran, pendekatan yang dipakai, perkembangan teknologi dan lainlain. Metode pembelajaran fisika biasanya adalah metode ceramah (lecturing) dan berpusat pada guru. Siswa pasif dalam proses pembelajaran. Hal yang lebih baik adalah dengan melakukan eksperimen dengan metode inquiry yang menghadapkan siswa kepada fenomena fisika.
Power teaching atau disebut juga Whole Brain Teaching adalah sebuah metode pembelajaran yang dikembangkan oleh Chris Biffle di Crafton Hills College Philosophy and Religious Studies II7II Sand Canyon Rd. Yucaipa, California. Jika dikaji lebih lanjut metode ini merupakan penyempurnaan metode ceramah dalam proses pembelajaran sehingga proses pembelajaran lebih efektif dan efisien. Tidak hanya guru saja yang aktif melakukan ceramah akan tetapi siswa juga melakukan tutor terhadap teman sebayanya. Hal ini membuat siswa menjadi lebih memahami dan mengingat apa yang diajarkan karena pada prosesnya siswa tidak hanya diam melainkan dapat fokus ke guru dan akhirnya mengajarkan kepada siswa lainya.

Tujuan kajian ini adalah dalam rangka untuk mempelajari metode pembelajaran "power teaching" dikaitkan dengan kerucut pengaman Edgar Dale dan pembahasan kemungkinan penggunaanya pada pembelajaran sains terutama fisika. 


\section{Pembelajaran dengan Metode Power Teaching}

Power teaching atau disebut juga Whole Brain Teaching adalah sebuah metode pembelajaran yang dikembangkan oleh Chris Biffle seorang professor di Crafton Hills College California. Pembelajaran dengan menggunakan metode ini telah banyak digunakan oleh berbagai guru dan dosen di mancanegara. Beberapa contohnya adalah Dr. Sue Brown, principal Fairfax Elementary School San Bernardino, California dan Cindy Fife 9th \& 10th Grades Los Osos High School. Keduanya mengatakan bahwa Metode Power teaching ini sangat membantu dalam proses pembelajaran dan memberikan perubahan yang besar dalam dunia pendikan terutama proses pembelajaran. Alexis Kelso guru di Fifth Grade Intern Park Forest Elementary Louisiana mengatakan bahwa " The strategies of Power teaching have improved student response and have also made it more engaging for students". Strategi Power teaching dapat meningkatkan respon siswa dan lebih menarik bagi siswa. Selain itu banyak lagi dosen dan guru yang menggunakan Power teaching ini di berbagai negara. Contohnya adalah Liann Nutini dari Canada (Canadian Teacher Magazine, 2012), Josie Woon dari New Zealand dll. Metode ini kurang berkembang di Indonesia.

Tabel I. Langkah-langkah Metode Pembelajaran Power

\begin{tabular}{cll}
\multicolumn{2}{c}{ teaching } \\
\hline No & Langkah & Fungsi \\
\hline I & Class "Yes" & Penarik perhatian \\
2 & Classroom rules & Pengorganisasian kelas \\
3 & Teach "Okay" & Pengaktivasi seluruh bagian otak \\
4 & The Scoreboard & Motivator \\
5 & Hands and eyes & Penekanan/pemfokus perhatian \\
6 & Switch & Pengembangan aktivitas mendengar \\
& & dan berbicara \\
\hline
\end{tabular}

Menurut Chriss Biffle (2008) penggagas awal Power teaching, terdapat 6 langkah besar dalam proses pembelajaran ini (lihat tabel I). Langkah-langkah metode pembelajaran Power teaching adalah

I. Class "Yes"

Langkah pertama dalam metode pembelajaran Power teaching adalah memfokuskan perhatian siswa. Guru mengucapkan "class" dan siswa menjawab "yes". Jika guru mengucapkan "class, class" maka siswa menjawab "yes, yes". Guru boleh juga mengucapkan "classity, classity" dan siswa menjawab "yessy,yessy" dst. Intensitas dan tone guru juga dapat digunakan untuk menarik perhatian siswa. Jika guru mengucapkannya dengan tone tinggi maka siswa menjawab dengan tone tinggi juga, dan sebaliknya.
Hal ini sangat efektif digunakan untuk menarik perhatian siswa. Siswa akan fokus ke guru di awal proses pembelajaran. Saat siswa fokus kepada guru inilah saat yang tepat dimanfaatkan guru untuk menjelaskan berbagai konsep yang diinginkan. Proses ini dapat dilakukan sepanjang proses pembelajaran untuk memfokuskan perhatian siswa ke guru. Siswa yang menjawab "yes" akan siap untuk menerima berbagai informasi yang akan diberikan oleh guru.

2. Classroom rules (aturan di dalam kelas)

Lima aturan di dalam kelas ini berfungsi sebagai pengorganisasi kelas. Kelas akan lebih terorganisir dengan adanya aturan yang berlaku didalam kelas. Lima aturan yang harus diberikan didalam kelas dalam metode Power teaching adalah

Ikuti petunjuk dengan cepat (Rule I: Follow directions quickly)

Guru memberikan instruksi dan siswa harus melakukan apa yang diinstruksikan oleh guru dengan cepat. Instruksi ini dapat berupa apapun termasuk buka buku, membaca keras, menggerakkan tangan, tepuk tangan, meminta siswa fokus ke papan tulis, meminta siswa mengulang apa yang disampaikan, meminta siswa mengajar ke teman terdekatnya dan lain-lain.

Pada awal pembelajaran Power teaching cara mengenalkan aturan ini adalah guru memberikan satu telunjuk ke atas, menggerakkan tangan ke depan, menunjukkan kepada siswa dan mengatakan "aturan pertama/rule I : ikuti petuntuk dengan cepat”. Kemudian siswa menirukan gerakan tangan guru dan mengucapkan "aturan pertama/rule I : ikuti petuntuk dengan cepat".

Angkat tanganmu jika ingin berbicara (Rule 2: raise your hand for permission to speak)

Siswa diminta untuk mengangkat tangan terlebih dahulu jika ingin mengutarakan pendapat atau menanyakan segala sesuatu yang kurang dipahami. Cara yang digunakan untuk mengenalkan aturan ini sama dengan cara mengenalkan aturan pertama kepada siswa. Perbedaanya adalah pada telunjuk yang diperlihatkan ke siswa (dua telunjuk).

Angkat tangan jika ingin meninggalkan tempat duduk (Rule 3: Raise your hand for permission to leave your seat

Siswa diminta untuk mengangkat tangan saat ingin meninggalkan kelas. Cara yang digunakan untuk mengenalkan aturan ini sama dengan cara mengenalkan aturan pertama kepada siswa. Perbedaanya adalah pada telunjuk yang diperlihatkan ke siswa (tiga telunjuk).

Buat pilihan yang cerdas (Rule 4: Make smart choices)

Proses pembelajaran terkadang harus menggunakan pertanyaan yang berupa pilihan oleh karena itu pada aturan keempat ini siswa dapat memilih apa yang menjadi jawaban pertanyaan yang diajukan. Siswa diminta mengangkat 
tangan dan memilih jawaban yang menurut mereka benar. Cara yang digunakan untuk mengenalkan aturan ini sama dengan cara mengenalkan aturan pertama kepada siswa. Perbedaanya adalah pada telunjuk yang diperlihatkan ke siswa (empat telunjuk)..

Jagalah agar guru tetap senang (Rule 5 : Keep your dear teacher happy)

Siswa diminta untuk membuat guru tetap senang. Hal ini dilakukan agar siswa selalu fokus kepada guru dan mengikuti instruksi yang diberikan oleh guru. Hal ini berhubungan dengan langkah keempat dari metode Power teaching ini. Cara yang digunakan untuk mengenalkan aturan ini sama dengan cara mengenalkan aturan pertama kepada siswa. Perbedaanya adalah pada telunjuk yang diperlihatkan ke siswa (lima telunjuk) dan ditambah memberikan wajah senyum kepada siswa.

Strategi ini harus dikenalkan pada siswa terlebih dahulu. Di awal proses pembelajaran guru dapat memberikan instruksi kepada siswa untuk menghafal semua aturan. Pada proses pembelajaran guru hanya tinggal mengucapkan aturan-aturan yang dilanggar atau yang diikuti oleh siswa dan siswa diharapkan memahaminya.

\section{Teach "Okay" (Ajar "Oke")}

Tahapan ini merupakan tahapan dimana seluruh bagian otak difungsikan (whole brain teaching). Seluruh bagian otak difungsikan pada tahapan ini. Tahapan ini merupakan tahapan aktivasi seluruh bagian otak untuk digunakan dalam proses pembelajaran. Tahapan ini dibagi menjadi tiga bagian yaitu

Bagian pertama adalah memfokuskan perhatian siswa dengan menggunakan Class "Yes". Hal ini akan memfokuskan perhatian siswa.

Bagian kedua adalah memberikan instruksi atau apapun yang diinginkan guru agar siswa belajar. Hal ini dapat dilakukan dengan memerintahkan siswa membuka buku, membaca, memperhatikan penjelasan konsep dari guru dan lain-lain. Informasi yang diberikan kepada siswa hendaknya tidak terlalu banyak agar siswa tidak bingung dan sulit untuk mengulang. Gunakan bahasa yang jelas dan tegas agar siswa dapat memahami secara cepat apa yang disampaikan.

Bagian ketiga adalah bertepuk tangan dua kali dan mengatakan "Teach" dan siswa menjawab "Okay". Sebelumnya siswa dijelaskan bahwa saat guru mengatakan "Teach" maka siswa harus menjelaskan apa yang diberikan guru kepada pasanganya. Sebelumnya pastikan siswa mendapatkan pasangan atau kelompok maksimal 3 orang dan minimal 2 orang.

4. Scoreboard (papan skor)

Scoreboard terdiri dari dua bagian, bagian pertama adalah bagian sedih dan bagian kedua adalah bagian gembira. Sedih dan gembira dapat diperlihatkan dalam gambar wajah sederhana di papan tulis. Pelanggaran aturan oleh siswa akan diberikan poin pada scoreboard bagian sedih dan siswa dapat juga mengatakan "booooo...." atau yang lainya untuk mengekspresikan sedih. jika siswa mengikuti apa yang diintruksikan maka guru memberikan poin pada scoreboard bagian senang dan siswa dapat mengatakan "yeah...." atau lainya untuk mengekspresikan kegembiraan. Berikan point pada scoreboard yang dibuat di depan kelas dan bergambar wajah senyum dan sedih sesuai dengan apa yang terjadi di dalam kelas. Scoreboard ini berfungsi untuk memotivasi siswa dalam proses pembelajaran.

5. Hands and eyes (tangan dan mata)

Tahapan ini dilakukan agar siswa tidak bosan hanya menggunakan class "yes" terus menerus. Dengan mengatakan "hands and eyes" siswa diminta untuk melihat ke depan dan mengangkat tangan ke atas. Hal ini untuk lebih memfokuskan perhatian siswa. Dalam proses ini dapat diterapkan jika konsep yang akan dijelaskan penting atau merupakan kesimpulan dari konsep-konsep yang dijelaskan sebelumnya. Kata hands and eye dapat diganti mata dan tangan atau yang lain. Pada proses ini dapat juga ditambahkan "Mirror" atau cermin dimana siswa menirukan gerakan tangan atau semua gerakan guru yang nantinya dapat digunakan dalam menjelaskan kepada siswa lainya. Hal ini akan meningkatkan daya ingat siswa karena tidak hanya mendengar saja tetapi juga mengingat melalui gerakan.

6. Switch (ganti)

Swicth dilakukan agar siswa bergantian menjelaskan kepada siswa lain. Hal ini dapat meningkatkan kemampuan siswa dan daya ingat siswa dalam memahami konsep. Guru dapat berkeliling di dalam kelas untuk mengecek bagimana siswa menjelaskan kepada pasanganya dan memastikan tidak terjadi miskonsepsi. Pada saat "teach -okay" hanya salah satu saja siswa yang menjelaskan. Kemudian ditambahkan "Swicth" agar siswa yang dijelaskan menjelaskan kembali apa yang telah dia dengarkan. Pada tahap ini siswa melatih diri mereka untuk mendengarkan dan menjelaskan (berbicara).

Seluruh langkah-langkah ini diharapkan dapat meningkatkan efektivitas belajar di kelas. Siswa menjadi fokus kepada guru dengan Class 'Yes". Organisasi kelas diatur dalam aturan yang diterapkan. Setelah siswa memahami apa yang diajarkan guru, konsep yang dikuasainya dikuatkan dengan mengajarkanya kepada teman sebayanya (teach "okay"). Scoreboard memberikan motivasi kepada siswa agar selalu medapatkan penghargaan dari guru berupa poin di papan tulis. Hands and eyes merupakan penekanan pada konsep yang penting. Switch melatih kemampuan berbicara dan mendengarkan. Langkah- 
langkah pembelajaran Power teaching ini dapat divariasikan sesuai dengan kebutuhan di dalam kelas.

\section{Pembahasan}

Power teaching sebagai alternatif metode pembelajaran dapat diterapkan untuk proses pembelajaran sains. Pada pembelajaran sains terutama fisika beberapa konsep dapat disampaikan dengan metode ini. Beberapa hal perlu diperhatikan dalam menerapkan metode ini dalam proses pembelajaran sains antara lain :

I. Konsep yang mudah dipahami dapat diajarkan langsung oleh guru.

Proses pembelajaran yang cepat dalam Power teaching menuntut kemampuan penyampaian konsep yang mumpuni oleh guru kepada siswa. Konsep yang mudah dipahami oleh siswa dapat diajarkan langsung oleh guru.

2. Konsep yang cukup sulit dapat diajarkan dengan memerintahkan siswa membaca dan memahami kemudian baru mengajarkan kepada teman sebayanya.

Konsep yang sulit harus dipelajari lebih lama oleh siswa. Guru dapat memerintahkan siswa untuk membaca terlabih dahulu di rumah atau sebelum pelajaran dimulai. Diharapkan dengan demikian pada saat Power teaching dilakukan siswa dapat lebih cepat memahami dan dapat mengikuti proses pembelajaran dengan baik.

3. Evaluasi hendaknya dapat dilakukan untuk mengecek pemahaman siswa karena pembelajaran yang tergolong cepat dan kemungkinan terjadi miskonsepsi.

Power teaching menuntut siswa agar cepat memahami dan mengajakan kepada teman sebayanya. Apabila siswa mengalami miskonsepsi maka siswa yang diajar juga akan mengalami miskonsepsi yang sama. Evaluasi setelah selesai memberikan konsep sangat penting agar miskonsepsi tidak terjadi. Evaluasi singkat ini dapat kita lakukan dengan menanyakan beberapa hal secara acak kepada siswa.

4. Konsep diajarkan secara bertahap dimana setiap tahapan dijelaskan oleh guru dan dipahami oleh siswa sehingga siswa mendapatkan pemahaman yang utuh dan dimengerti pada akhirnya.

Akibat proses pembelajaran Power teaching yang cepat maka konsep yang sulit dapat diajarkan dengan bertahap. Berbeda dengan pembelajaran biasa yang memberikan konsep secara utuh, dalam Power teaching konsep dapat dipecah menjadi bagian-bagian kecil yang mudah dimengerti oleh siswa. Bagian-bagian ini kemudian disimpulkan di akhir proses pembelajaran sehingga manjadi utuh.

5. Materi yang terlampau sulit bagi siswa harus dipikirkan ulang bagaimana menganjarkanya kepada siswa dengan metode ini.
Apabila materi terlampau sulit maka harus dipikirkan apakah metode ini cocok untuk menyampaikan materi tersebut atau tidak. Harus dipikirkan kembali bagaimana mengajarkan materi yang terlampau sulit tersebut kepada siswa.

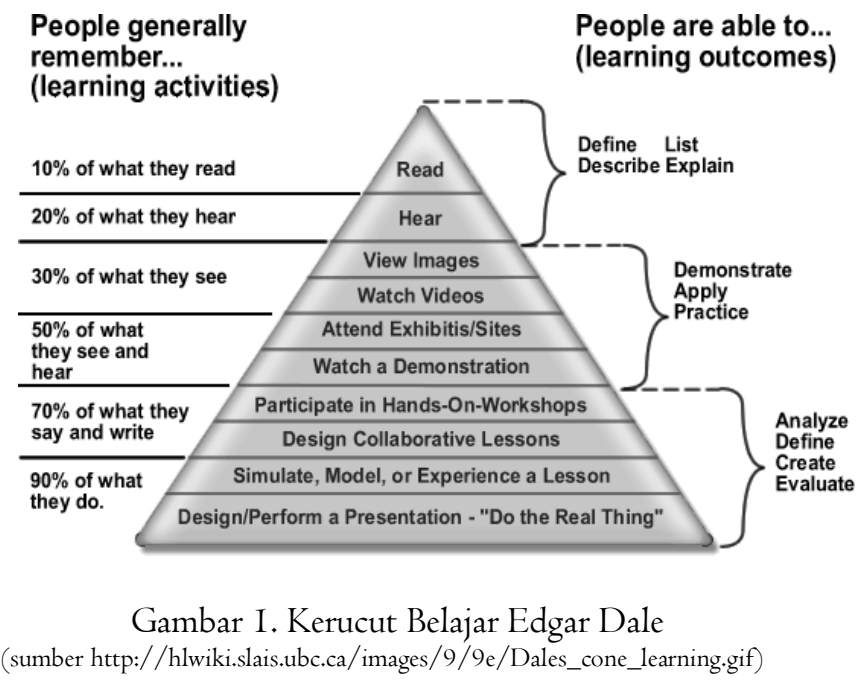

Berdasarkan kerucut pembelajaran Edgar Dale yang telah umum dikenal Power teaching memberikian kontribusi 70$90 \%$ dari apa yang dikatakan dan dilakukan karena siswa melakukan pembicaraan (giving a talk) atau presentasi dramatik kepada siswa lainya (gambar I).

Proses pembelajaran dengan menggunakan metode ini siswa tidak hanya dituntut untuk memahami secara cepat apa yang disampaikan oleh guru akan tetapi juga menjelaskan konsep yang diajarkan oleh guru kepada siswa lainya. Oleh karena itu guru harus memastikan siswa memahami konsep yang disampaikan. Hal ini dapat dilakukan dengan menunjuk secara acak siswa untuk menjelaskan konsep yang diajarkan dan mengurangi kosakata dan konsep yang diberikan (sepotong-sepotong).

Kelebihan dari metode Power teaching ini adalah perhatian dan fokus siswa selalu tertuju kepada guru. Dengan siswa fokus dan perhatian hanya kepada guru, proses penyampaian informasi kepada siswa menjadi lebih optimal. Kelebihan lain dari metode ini adalah siswa mendapatkan penguatan pada proses pengulangan konsep dan pada saat mengajarkanya kepada teman sejawatnya.

Menurut Azimatul Ifah dan Rusjiono (2010) pembelajaran tutor teman sebaya merupakan metode pembelajaran yang berpusat pada siswa, dalam hal ini siswa belajar dari siswa lain yang memiliki status umur dan kematangan/harga diri tidak jauh berbeda sehingga anak tidak begitu terpaksa menerima ide-ide dan sikap dari "gurunya" yang tidak lain adalah teman sebayanya sendiri. Hal ini berbeda dengan metode Power teaching. Dalam 
Metode Power teaching siswa dipaksa memahami dan mengajarkan konsep yang diberikan oleh guru dengan cara yang menyenangkan. Kenyamanan dalam belajar dalam kedua meode ini tidak dikesampingkan.

Peran masing-masing tahap dalam proses pembelajaran dengan metode Power teaching menurut Jeff Battle, Director, North Carolina Whole Brain Teachers dalam website http://www.wholebrainteaching.com adalah

\section{Class Yes}

Mengaktifkan prefrontal cortex, pusat penalaran otak. Area ini dapat kita anggap sebagai "saklar" yang harus dibuka berulang_ulang dengan class-yes” untuk agar otak siap memproses informasi.

2. Classroom rules (aturan di dalam kelas)

Lima aturan kelas ketika dilatih dan digunakan di kelas, lima aturan melibatkan korteks prefrontal, area Broca, Area Wernicke, sistem limbik, hipokampus, korteks visual dan motorik korteks.

\section{Teach "Okay"}

Teach-Oke adalah yang paling kuat Kegiatan belajar Daya Pengajaran ini. Siswa memiliki korteks prefrontal terlibat, mengaktifkan Area Broca karena mereka berbicara, mengaktifkan daerah Wernicke karena mereka mendengar, mengaktifkan visual dan korteks motorik seperti yang mereka lihat dan membuat gerakan. Kegiatan ini seluruh merangsang hipokampus otak dengan kuat untuk membentuk ingatan jangka panjang.

4. The scoreboard

Scoreboard juga merupakan bagian penting dari metode pembelajaran. Scoreboard merupakan kunci menuju area sistem emosi limbik yang mengarah ke kenyamanan (senang) dan sedih saat siswa mendapatkan hukuman atau penghargaan.

5. Hands and eyes (tangan dan mata)

Tangan dan Mata memfokuskan seluruh aktivitas mental di melihat dan mendengar materi guru yang diajarkan. Mirror (pencerminan) mengaktifkan korteks visual dan motorik ,serta neuron pencerminan di daerah otak lain yang merupakan pusat juga.

6. Switch (ganti)

Switch membantu siswa sepenuhnya untuk mengembangkan kemampuan berbicara (area Broca) dan kemampuan mendengarkan (area Wernicke) mereka.

Keenam langkah Power teaching di atas memberikan pengalaman belajar baik dari segi mental, motorik dan kognitif karena terdapat aktivitas yang mengarah ke motorik, mental dan kognitif.

\section{Kesimpulan}

Power teaching adalah metode pembelajaran dengan mengacu pada lima langkah pembelajaran yaitu

I. Class "Yes"

2. Classroom rules (aturan di dalam kelas)

3. Teach "Okay" (Ajar "Oke")

4. The Scoreboard

5. Hands and eyes (tangan dan mata) dan Mirror (pencerminan)

6. Switch

Power teaching sesuai dengan kerucut pengalaman Edgar Dale dan memberikan kontribusi kontribusi 70-90 \% dari apa yang dikatakan dan dilakukan karena siswa melakukan pembicaraan (giving a talk) atau presentasi dramatik kepada siswa lainya. Metode Power teaching ini cocok digunakan dalam proses pembelajaran sains dengan memperhatikan beberapa hal berikut ini:

I. Konsep yang mudah dipahami dapat diajarkan langsung oleh guru.

2. Konsep yang cukup sulit dapat diajarkan dengan memerintahkan siswa membaca dan memahami kemudian baru mengajarkan kepada teman sebayanya.

3. Evaluasi hendaknya dapat dilakukan untuk mengecek pemahaman siswa karena pembelajaran yang tergolong cepat dan kemungkinan terjadi miskonsepsi.

4. Konsep diajarkan secara bertahap dimana setiap tahapan dijelaskan oleh guru dan dipahami oleh siswa sehingga siswa mendapatkan pemahaman yang utuh dan dimengerti pada akhirnya.

5. Materi yang terlampau sulit bagi siswa harus dipikirkan ulang bagaimana menganjarkanya kepada siswa dengan metode ini.

\section{Kepustakaan}

Alexis Kelso, 2009, Power teaching: "How Powerful Is It?", Fifth Grade Intern Park Forest Elementary Luisiana

Azimatul Iffah, Rusijono, 20I0, Pengaruh pembelajaran tutor teman sebaya terhadap hasil belajar TIK, Kurikulum dan teknologi pendidikan, Universitas Negeri Surabaya.

Chris Biffle, 2008, 60 Power teaching case studies, Philosophy Department Crafton Hills College Yucaipa, California

Chris Biffle, 2008, Power Teachers Training Manual, Crafton Hills College Philosophy and Religious Studies Sand Canyon Rd.,Yucaipa, California

Ihat Hatimah, 2008, Pengertian Pendekatan, strategi, metode, teknik, taktik dan model http://file.upi.edu/Direktori/FIP/JUR._PEND._LU 
AR_SEKOLAH/I9540402I980II200I-

IHAT_HATIMAH/Pengertian_Pendekatan,_strategi, metode,_teknik,_taktik_dan.pdf, diunduh pada 4 mei 2013 pukul 10.00

Jeff Battle, 2008, Attention Getter: Class-Yes, Director, North Carolina Whole Brain Teachers, http://www.wholebrainteaching.com/index.php?option =com_k2\&view $=$ item\&layout $=$ item\&id $=159$ \&Itemid $=$ I25 Diakses tanggal 5 mei 20I4, pukul I3.00

Liann Nutini, 2012, Whole Brain Teaching A New Way of Life, Canadian Teacher Magazine

PISA, 2009, Student Performance in Reading, Mathematics and Science, OECD, PISA 2009 Database 